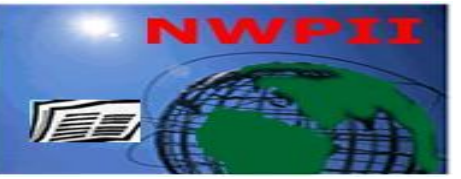

American Journal of Biomedical Sciences

ISSN: 1937-9080

nwpii.com/ajbms

\title{
Stability of Freeze-dried Inactivated Japanese Encephalitis Vaccine under Different Experimental Conditions
}

\author{
Dipa Gowal*, Sandeep Kumar and Amrita Sharma
}

Japanese Encephalitis Vaccine Division, Quality Control Section, Central Research Institute, Kasauli, H.P., India173204

*Corresponding Author

Dr. (Mrs.) Dipa Gowal, M.Sc., M.Phil., Ph.D. (Microbiology)

Dy. Asst. Director

Japanese Encephalitis Vaccine Division,

Quality Control Section,

Central Research Institute,

Kasauli, H.P., India-173204.

Phone: +91 1792272203 (Office);

+919418082203 (Mobile)

Email: gill.microbiologist@ rediffmail.com

Received: 1 October 2009; | Revised: 7 January 2010; | Accepted: 13 January 2010

\begin{abstract}
Stability of three batches of freeze dried inactivated mouse brain Japanese encephalitis vaccine, was evaluated in terms of percentage drop or otherwise in potency from their respective initial titers, after exposure to different experimental conditions for 4-12 weeks. The potency was assayed by plaque reduction neutralization assay (PRNT) using chick embryo fibroblasts cells. The vaccine has been found to be stable i.e. retain potency (mean drop 3.99\%) till 12 weeks when exposed at $25^{\circ} \mathrm{C} \pm 2{ }^{0} \mathrm{C}$ and $80-90 \%$ relative humidity (RH). At $37^{\circ} \mathrm{C} \pm 1{ }^{0} \mathrm{C}$ and when kept in vertical position, the vaccine showed an average drop of $10.42 \%$ in potency after 12 weeks, while it was $11.0 \%$ and $10.42 \%$ in horizontal positions and inverted position respectively. Exposure at higher temperature $\left(45^{\circ} \mathrm{C} \pm 1{ }^{\circ} \mathrm{C}\right.$ and $\left.80-90 \% \mathrm{RH}\right)$ led to deterioration of potency $(25.82 \%)$ after 8 weeks. A maximum average drop of $7.66 \%$ in potency was observed when vaccine was exposed to sunlight compared to $4.29 \%$ in case of artificial light after 12 weeks indicating that the JE vaccine should not be exposed to direct light. Thus, even if this vaccine gets exposed to higher temperature for a short duration, it appears that FD JE vaccine may be potent enough for effective seroconversion in the field.
\end{abstract}

Keywords: JE vaccine; stability; potency. 


\section{Introduction}

Japanese encephalitis is a mosquito-borne arboviral disease and is a public health problem particularly in India with high morbidity and mortality. Worldwide three types of inactivated vaccines are in widespread production and use. In India, formalized mouse brain JE vaccine has been in use since 1987. India has produced an effective and safe freeze dried JE vaccine from mouse brain source using Nakayama NIH JE virus strain, which has been found to be highly potent, safe and stable vaccine. Efficacy and safety of this vaccine has been studied and result showed 100\% seroconversion after two doses and neutralizing antibody titer was raised further after booster doses in population residing in Kasauli, a nonendemic area of JE [1].

Stability is a major requirement for any biological/ biotechnological product since safety and efficacy are directly related to it. Stability, in case of vaccines, is defined as the shelf life of 2 years or more. Shelf life is the time point up to which the product remains $90 \%$ active or efficacious. Stability tests are required, therefore, to predict the length of time during which the product is expected to retain an acceptable level of potency [2].

The accelerated stability test is the most widely used method of predicting the stability of a biological product. Some of the other methods intended to be included are: Potency, purity, molecular characterization, degradation products etc. Other product characteristics such as: Visual appearance of product (colour and opacity for solutions, suspension colour, texture and dissolution time for powder), visual particulates in solution or after the reconstitution of powders or lyophilized cakes, $\mathrm{pH}$ and moisture level of powders and lyophilized products should also be monitored [3].

In order to maintain the required potency, the storage facility should be adequate to maintain the required storage conditions $\left(4-10^{\circ} \mathrm{C}\right)$. A good vaccine should retain immunogenicity for longer periods at temperature less than $10^{\circ} \mathrm{C}$ and also above ambient. In case of FD JE vaccine the shelf life is 5 years which depends upon the retention of the potency below $10^{\circ} \mathrm{C}$. It has been observed that the vaccine retains potency even upto 5.5 years thereafter showing decline (data not shown). As per the WHO requirements for JE vaccine, FD JE vaccine should retain its potency when stored at $37^{0} \mathrm{C}$ for 4 weeks [4]. However, because of poor storage facilities in most tropical countries, the vaccines may get exposed to the ambient temperature. Since limited data/published literature are available on the stability of JE vaccine, the present study was aimed at evaluating its stability in terms of potency under different experimental conditions.

\section{Materials and methods}

\subsection{J.E. virus strains}

The Nakayama NIH strain of J.E. virus, originally supplied by Dr. Akira Oya, Deputy Director General, National Institute of Health, Tokyo, Japan was used in this study.

\subsection{J.E. Stock Virus}

It was prepared as mentioned in the Minimum Requirement for JE vaccine $[4,5,6]$.

\subsection{JE Vaccine}

Three batches of freeze dried JE vaccine (21 vials of each) were included in the study. These batches were labeled as test vaccine ' $\mathrm{T} 1$ ' and ' $\mathrm{T} 2$ ' and ' $\mathrm{T} 3$ '.

\subsection{Hyper immune Sera}

A hyper immune serum of known titer served as the positive control in the PRNT assay. This was raised in rabbits against JE (Nakayama NIH) virus as per the method of Yoshika et al. [7].

\subsection{Potency assay of JE Vaccine}

To study the effect of different experimental conditions on the stability of JE vaccine, the vaccine vials were exposed to different experimental conditions viz. $25^{\circ} \mathrm{C} \pm 2{ }^{\circ} \mathrm{C}$ and 80 $90 \%$ relative humidity $(\mathrm{RH}) ; 37^{\circ} \mathrm{C} \pm 1^{\circ} \mathrm{C}$ and $80-$ $90 \% \mathrm{RH}$ (in vertical, horizontal and inverted positions); $45^{\circ} \mathrm{C} \pm 1^{\circ} \mathrm{C}$ and $80-90 \% \mathrm{RH}$; sunlight and artificial light, for $4-12$ wks. Potency assay was performed on each batch, after $4^{\text {th }}, 8^{\text {th }}$ and $12^{\text {th }}$ week of exposure, as per the Minimum Requirements for JE vaccine $[4,5,6]$. Potency 
was determined by estimating the JEV neutralizing antibodies (NT-Ab) response in a group of immunized mice by plaque reduction neutralization test (PRNT) on chick embryo fibroblast cells monolayer as per the method of Oya et al. [8]. The PRNT titer was defined as the reciprocal of the serum dilution that resulted in a $50 \%$ reduction in plaque number and was calculated as: $\mathrm{Z}=(\mathrm{Y}-50) / 47.7622+\log \mathrm{X}$, where $\mathrm{Z}$ : NT-Ab titer $\left(\log _{10}\right), \mathrm{Y}$ : plaque reduction rate $(\%), \mathrm{Y}=10-90 \%, \mathrm{X}$ : reciprocal of serum dilution used [9, 10]

As per the WHO requirement, the test vaccine is said to have passed the test when its potency is equal to or more than the reference vaccine. All the vaccine batches tested had potency more than the reference vaccine (procured from NIH, Tokyo, Japan), which is the Japanese National Standard for JE vaccine. The effect of above conditions over stability was evaluated from the extent of drop in the potency as compared to their respective initial potency (relative potency).

\section{Results and discussion}

Thermo stability of JE vaccine, stored under different experimental conditions for varying time periods, was evaluated by estimating the drop or otherwise in the potency level and percentage of drop with relation to its initial potency. Potency was expressed in terms of Neutralizing antibody titer $\log _{10}$. The assessment of the protective efficacy of the vaccine was evaluated by comparing the final potency of the test vaccine (after 4, 8, 12 weeks of exposure) with that of the reference vaccine. The results (Table 1) showed a gradual fall in potency level (NT-Ab titer $\log _{10}$ ), though insignificant (ranging between $3.5-4.63 \%$ maximum), after 12 weeks of exposure at $25 \pm$ $2^{0} \mathrm{C}$ and $80-90 \% \mathrm{RH}$ as compared to initial potency in all the three batches. Similar findings were reported by Gowal et al. [11] where a maximum of $8.7 \%$ drop in potency after 28 weeks of exposure at $22^{\circ} \mathrm{C}$ was observed. Tsai et al. [12] and Halstead \& Tsai [13] also observed that Biken vaccine retains more than $90 \%$ of its potency after 28 weeks at $22^{\circ} \mathrm{C}$. At $37^{\circ} \mathrm{C}$, lyophilized vaccine retains $95 \%$ of its original potency after 4 weeks. A moderate loss of potency was demonstrated after liquid JE vaccine was exposed to simulated field conditions [14]. Though the exposure temperature in the present study was a bit higher still the fall in potency was quite low. Further, the vaccine potency after 12 weeks of exposure was still higher than the reference vaccine (except in Batch - T2 where initial potency was found comparable to that of the reference vaccine) which clearly shows that the vaccine is stable under this condition. Further work, however, may be required in order to predict the length of time for which the vaccine retains the adequate potency level for the time period extended beyond 12 weeks at this temperature.

With increase in the temperature it was found that the percentage drop in potency varied directly as the duration of exposure. At $37^{\circ} \mathrm{C} \pm 1^{\circ} \mathrm{C}$ and 80 $90 \% \mathrm{RH}$ and under different positions of the vials (vertical, horizontal and inverted), the average drop in potency reached to between 10.42-11.00\% after 12 weeks in all the batches of FD JE vaccine (Table 1,2). These findings are in accordance with the work of Gowal et al. [11] wherein a maximum drop of $13.67 \%$ after 18 weeks was observed. No significant effect of storing the vials in different positions was observed since the percentage drop in potency in all the three batches was found to be similar after completion of the exposure time period. As per the $\mathrm{WHO}$ requirements, the vaccine should retain its potency when stored at $37^{\circ} \mathrm{C} \pm 1^{0} \mathrm{C}$ for 4 weeks [4]. In the present study the vaccine was found to be potent under this condition i.e. retain potency greater than that of the reference vaccine till $8^{\text {th }}$ week only (Batch T2 \& T3 showed titers comparable to the reference vaccine) thereafter showing a decline indicating thereby the loss of stability of the vaccine at $37^{\circ} \mathrm{C} \pm 1^{0} \mathrm{C}$.

$\mathrm{JE}$ vaccine showed good stability at $25^{\circ} \mathrm{C} \pm 2^{0} \mathrm{C}$ and $37^{\circ} \mathrm{C} \pm 1^{\circ} \mathrm{C}$, however, at $45^{\circ} \mathrm{C} \pm 1^{\circ} \mathrm{C}$ and 80 $90 \% \mathrm{RH}$ the potency deteriorated quite fast i.e. average drop in potency reached $25.82 \%$ after 8 weeks of exposure (Table 2). The results of this study correlates with the work of Gowal et al. [11] that the potency deteriorated quite fast after 4 weeks at $40^{\circ} \mathrm{C}$. The vaccine retained the potency or did not show a significant fall for 2 weeks at $40^{\circ} \mathrm{C}$ (only $9.64 \%$ drop), but thereafter the percentage drop had risen to 26.64 after 6 weeks of exposure. In the present study, the exposure

\footnotetext{
(C) 2010 by NWPII. All rights reserved. 
time was extended up to 12 weeks at $45^{0} \mathrm{C} \pm 1^{0} \mathrm{C}$ and $80-90 \% \mathrm{RH}$, however, the potency was not evaluated after 8 weeks as the vaccine failed compared to the reference vaccine and also a significant drop in potency ranging from $23.83 \%$ to $26.78 \%$ was observed in all the three batches, suggesting thereby the detrimental effect of exposure at higher temperature for longer time period.

Table 1. Potency of three batches of freeze dried inactivated mouse brain JE vaccine under different experimental conditions.

\begin{tabular}{|c|c|c|c|c|c|c|c|c|c|c|}
\hline \multirow{3}{*}{$\begin{array}{c}\mathrm{JE} \\
\text { vaccine }\end{array}$} & \multirow{2}{*}{\multicolumn{2}{|c|}{$\begin{array}{r}\text { Initial Potency } \\
\left.\text { (NT-Ab } \log _{10}\right)\end{array}$}} & \multirow{3}{*}{$\begin{array}{l}\text { Time } \\
\text { Period } \\
\text { (wks) }\end{array}$} & \multicolumn{7}{|c|}{ Potency (NT-Ab titer $\log 10)$} \\
\hline & & & & \multirow[t]{2}{*}{$25^{\circ} \pm 2{ }^{\circ} \mathrm{C}$} & \multicolumn{3}{|c|}{$37^{\circ} \pm 1^{\circ} \mathrm{C}$} & \multirow[t]{2}{*}{$45^{\circ} \pm 1^{\circ} \mathrm{C}$} & \multirow[t]{2}{*}{ Sunlight } & \multirow[t]{2}{*}{ Artificial light } \\
\hline & $\begin{array}{c}\text { Test } \\
\text { Vaccine }\end{array}$ & $\begin{array}{c}\text { Ref. } \\
\text { Vaccine }\end{array}$ & & & Vertical & Horizontal & Tnverted & & & \\
\hline \multirow[t]{3}{*}{ Batch-T1 } & 2.371 & 2.141 & 4 & $2.351\left(0.84^{0}\right)$ & $2.330(1.73)$ & $2.309(2.61)$ & $2.330(1.73)$ & $2.162(8.81)$ & $2.288(3.5)$ & $2.351(0.84)$ \\
\hline & & & 8 & $2.330(1.73)$ & $2.204(7.04)$ & $2.225(6.16)$ & $2.183(7.93)$ & $1.806(23.83)$ & $2.246(5.27)$ & $2.309(2.61)$ \\
\hline & & & 12 & $2.288(3.5)$ & $2.099(11.47)$ & $2.078(12.36)$ & $2.120(10.58)$ & ND & $2.183(7.93)$ & $2.267(4.38)$ \\
\hline \multirow[t]{3}{*}{ Batch-T2 } & 2.183 & 2.141 & 4 & $2.162(0.96)$ & $2.162(0.96)$ & $2.141(1.92)$ & $2.141(1.92)$ & $1.995(8.6)$ & $2.120(2.88)$ & $2.162(0.96)$ \\
\hline & & & 8 & $2.141(1.92)$ & $2.037(6.68)$ & $2.057(5.77)$ & $2.016(7.65)$ & $1.597(26.84)$ & $2.037(6.68)$ & $2.120(2.88)$ \\
\hline & & & 12 & $2.099(3.84)$ & $1.953(10.53)$ & $1.974(9.57)$ & $1.953(10.53)$ & ND & $2.016(7.65)$ & $2.099(3.84)$ \\
\hline \multirow[t]{6}{*}{ Batch-T3 } & 2.267 & 2.141 & 4 & $2.267(0)$ & $2.225(1.85)$ & $2.246(0.92)$ & $2.225(1.85)$ & $2.057(9.26)$ & $2.183(3.7)$ & $2.246(0.93)$ \\
\hline & & & 8 & $2.225(1.85)$ & $2.141(5.56)$ & $2.120(6.48)$ & $2.099(7.41)$ & $1.660(26.78)$ & $2.141(5.56)$ & $2.183(3.7)$ \\
\hline & & & 12 & $2.162(4.63)$ & $2.057(9.26)$ & $2.016(11.07)$ & $2.037(10.14)$ & ND & $2.099(7.41)$ & $2.162(4.63)$ \\
\hline & Mean $\pm S D$ & & 4 & $2.260^{\circ} \pm 0.077,3.4^{\circ}$ & $2.239 \pm 0.069,3.1$ & $2.232 \pm 0.069,3.1$ & $2.232 \pm 0.077,3.5$ & $2.071 \pm 0.069,3.3$ & $2.197 \pm 0.069,3.2$ & $2.253 \pm 0.077,3.4$ \\
\hline & $(\mathrm{CV} \%)$ & & 8 & $2.232 \pm 0.077,3.5$ & $2.127 \pm 0.069,3.2$ & $2.134 \pm 0.069,3.2$ & $2.099 \pm 0.068,3.2$ & $1.688 \pm 0.088,5.2$ & $2.141 \pm 0.085,4.0$ & $2.204 \pm 0.079,3.6$ \\
\hline & & & 12 & $2.183 \pm 0.079,3.6$ & $2.036 \pm 0.061,3.0$ & $2.023 \pm 0.043,2.1$ & $2.037 \pm 0.068,3.3$ & ND & $2.099 \pm 0.068,3.2$ & $2.176 \pm 0.069,3.2$ \\
\hline
\end{tabular}

Initial mean potency of three batches of JE vaccine (Test vaccine) $=2.274 \pm 0.077(n=3, C V=3.4 \%)$

${ }^{a}$ Japanese National Reference Standard Vaccine;

${ }^{\mathrm{b}}$ Figure in parenthesis indicates percentage drop in titre compared to initial titre;

${ }^{c}$ Mean potency of $n=3$ values with 1 SD;

${ }^{\mathrm{d}}$ Coefficient of Variation.

ND - Not Done.

Because of poor storage facilities in most tropical countries these biological products may very often get exposed to the ambient temperature. In India, during the peak summers the temperature goes above $45^{\circ} \mathrm{C}$ in most parts of the country. Thus above results give a clear picture of the effect of temperature and experimental conditions on the vaccine.

From the study data it is clear that the vaccine can withstand temperature around $45^{\circ} \mathrm{C} \pm 1^{0} \mathrm{C}$ for up to 4 weeks without losing much potency (showing titres comparable to reference vaccine except Batch-T2) i.e. the product is stable. In actual practice, it is a rare condition that a vaccine may get exposed to such a higher temperature for long periods, but stills even if this happens, it is safe up to 4 weeks. These data with regard to stability of JE vaccine at different temperatures, simulating Indian conditions, will give ready information on the effects they have on the quality of the vaccine.

The effect of light (direct sunlight and artificial light) on the potency of vaccine was also evaluated after different time periods as mentioned earlier. The drop in potency after 12 weeks of exposure reached to an average $7.66 \%$ in case of the vaccine vials exposed to sunlight compared to $4.29 \%$ in the case of artificial light. On comparing the results it is evident that there is a considerable fall in potency in the first case (sunlight exposure) after 12 weeks while on the other hand no appreciable loss in potency occurred after exposure to artificial light during this time period. 
Although freeze dried JE vaccine can withstand elevated temperatures for a short duration of time, rigid cold storage conditions must be maintained particularly during transportation and at the delivery site so that a potent vaccine for effective seroconversion is available in the field. As there is scarcity of literature on stability studies of JE vaccine, this data would be helpful to the developing countries which are using inactivated mouse brain JE vaccine for immunization.

Table2: Percentage drop in potency in all the three batches of JE vaccine under different experimental conditions.

\begin{tabular}{|c|c|c|c|c|}
\hline \multicolumn{2}{|c|}{$\begin{array}{c}\text { Experimental } \\
\text { Conditions }\end{array}$} & 4 weeks & 8 weeks & 12 weeks \\
\hline \multirow[t]{2}{*}{$25^{0} \mathrm{C} \pm 2^{0} \mathrm{C}$} & & $0.90^{\mathrm{a}} \pm 0.428^{\mathrm{b}}$ & $1.84 \pm 0.080$ & $3.99 \pm 0.473$ \\
\hline & Vertical & $1.51 \pm 0.394$ & $6.43 \pm 0.633$ & $10.42 \pm 0.905$ \\
\hline \multirow[t]{2}{*}{$37^{\circ} \mathrm{C} \pm 1^{0} \mathrm{C}$} & Horizontal & $1.82 \pm 0.693$ & $6.14 \pm 0.291$ & $11.00 \pm 1.138$ \\
\hline & Inverted & $1.84 \pm 0.080$ & $7.66 \pm 0.212$ & $10.42 \pm 0.197$ \\
\hline $45^{\circ} \mathrm{C} \pm 1^{\circ} \mathrm{C}$ & & $8.9 \pm 0.272$ & $25.82 \pm 1.405$ & ND \\
\hline Sunlight & & $3.36 \pm 0.348$ & $5.84 \pm 0.611$ & $7.66 \pm 0.212$ \\
\hline $\begin{array}{c}\text { Artificial } \\
\text { light }\end{array}$ & & $0.91 \pm 0.050$ & $3.07 \pm 0.464$ & $4.29 \pm 0.327$ \\
\hline
\end{tabular}

${ }^{a}$ Mean of percentage drop in potency in all the three batches.

${ }^{\mathrm{b}}$ Standard deviation.

$\mathrm{ND}=$ Not Done

\section{References:}

[1] Rao Bhau, L.N.; Singh, G.; Gowal, D.; Saxena, S.N.; Kobayashi M, Oya A and Yoshioka I. Safety and efficacy of J.E vaccine produced in India, Indian J Med Res, 1988, 88, 301-307.

[2] Campbell, P.J. International Biological standards and reference preparation. I. Preparation and presentation of materials to serve as standards and reference preparation, J Biol Stand 1974, 2(4), 249-258.

[3] Quality of Biotechnological products: Stability testing of biotechnological/ biological products, ICH Q5C, July 1996.

[4] Requirement for Japanese Encephalitis Vaccine (Inactivated) for human use, WHO Tech Rep Series 1988, 771, 133-157.
[5] Minimum Requirement of JE Vaccine, Ministry of Health and Welfare, Government of Japan, Tokyo. 1986.

[6] Japanese Encephalitis Vaccine, Human (Mouse Brain), Indian Pharmacopeia, 2007, 1961-1964.

[7] Yoshioka, I.; Aizawa, C.; Yamagishi, H. and Kasahara, S. Antigenic differences of Japanese Encephalitis virus strains. In: Immunization for Japanese Encephalitis. Edited by Hammon, W.M.; Kitaoka, M. and Downs, W.G., Igaku Shoin Ltd., Tokyo. 1971; p 28.

[8] Oya, A.; Kan, K.; Kurokawan, M.; Oshida, S.A. A new formula for direct calculation of neutralizing antibody titer against Japanese encephalitis virus from plaque reduction rate on chick embryo tissue culture. In: $2^{\text {nd }}$ 
Report of Japanese vaccine research commission, 1967, 5-10 (In Japanese).

[9] Borges, M.B.J.; Kato, S.E.M.; Damaso, C.R.A.; Moussatche, N.; Freire M.S.; Passos, S.R.L. and Nascimento, J.P. Accuracy and repeatability of a micro plaque reduction neutralization test for vaccinia antibodies. Biologicals 2008, 36(2), 105-110.

[10] Abe, M.; Kuzuhara, S. and Kino, Y. Establishment of an analyzing method for a Japanese encephalitis virus neutralization test in Vero cells. Vaccine 2003, 21, 19891994.

[11] Gowal, D.; Singh, G.; Rau Bhau, L.N. and Saxena, S.N. Thermostability of JE vaccine produced in India. Biologicals 1990, 19, 3740.
[12] Tsai, T.F.; Chang G.J.J. and Yu, Y.X. Japanese encephalitis vaccines. In: Plotkin, S.A. and Orenstein, W.P., Vaccines, $3^{\text {rd }}$ Edition, W.B. Saunders Company, Pennysylvania, 1999, pp 672-710.

[13] Halstead, S.B. and Tsai, T.F. Japanese encephalitis vaccines. In: Plotkin, S.A. and Orenstein, W.P., Vaccines, $4^{\text {th }}$ Edition, W.B. Saunders Company, Pennysylvania, 2004, pp 919-958.

[14] Fukunaga, T.; Rojanasuphot, S.; Wungkorbkiat, S. Thammanichanon, A and kan T. Japanese encephalitis vaccination in Thailand. Biken J. 1974, 17(1), 21-31. 